\title{
ANÁLISES FÍSICO-QUIMICAS, SENSORIAIS E MICROBIOLÓGICAS DE NÉCTAR MISTO À BASE DE AÇAÍ, ACEROLA E MORANGO
}

\author{
PHYSICAL-CHEMICAL, SENSORIAL AND MICROBIOLOGICAL \\ ANALYSIS OF AÇAÍ, ANTILLE CHERRY AND STRAWBERRY MIXED \\ NECTAR
}

\author{
Bianca De Sousa Fernandes ${ }^{1}$, Eliza Dorotea Pozzobon De Albuquerque ${ }^{1}$, \\ Mauro Luiz Aldrigue ${ }^{1}$ \\ ${ }^{1}$ Faculdade de Ciências Médicas da Paraíba, João Pessoa, Paraíba, Brasil \\ "Autor Correspondente: Endereço: R. Radialista Antônio Assunção de Jesus, 1226, João \\ Pessoa- PB, CEP: 58052230 Telefone: (83) 996121671, Email: fernandes.bianc@hotmail.com
}

\section{RESUMO}

O consumo de bebidas prontas tem apresentado um significativo aumento ultimamente. O objetivo deste estudo foi avaliar qualidade, estabilidade e aceitabilidade de néctar misto nos seus aspectos físico-químicos, sensoriais e microbiológicos. O néctar misto foi elaborado de três polpas congeladas: açaí, acerola e morango, adquiridas em João PessoaPB. As análises físico-químicas realizadas a cada 30 dias por 90 dias foram: $\mathrm{pH}$; acidez total titulável (ATT); Sólidos Solúveis e Vitamina C; análises microbiológicas foram: coliformes totais e Salmonella sp. As análises sensoriais de aceitabilidade e intenção de compra foram realizadas com 40 provadores não treinados em duas amostras, uma a $24 \pm 2^{\circ} \mathrm{C}$ e outra em $15^{\circ} \mathrm{C}$. Os resultados do néctar misto foram: $19,8^{\circ} \mathrm{Brix}, \mathrm{pH} 2,83$, acidez total titulável $0,12 \%$ e vitamina C $139,75 \mathrm{mg} / 100 \mathrm{~mL}$ mantendo qualidade sanitária no período de armazenamento. O néctar misto obteve uma boa aceitabilidade nos atributos aparência, aroma e sabor, e médias 7,$63 ; 7,90 ; 8,08$, respectivamente, em temperatura ambiente; em temperatura de refrigeração médias 7,48; 7,60;8,10, respectivamente. A intenção de compra do néctar misto não teve diferença significativa em temperatura ambiente $(4,50)$ com a refrigerada $(4,58)$. O néctar misto permaneceu estável durante o armazenamento, uma boa fonte de vitamina $\mathrm{C}$ com uma boa aceitabilidade e intenção de compra.

Palavras-chave: Néctar. Néctar Misto. Açaí. Acerola. Morango.

\begin{abstract}
The consumption of ready-to-drink beverages has increased significantly lately. The aim of this study was to evaluate the quality, stability and acceptability of mixed nectar in its physicochemical, sensory and microbiological aspects. The mixed nectar was made from three frozen pulps: açaí, Antille cherry and strawberry, purchased in João PessoaPB. The physicochemical analyses performed every 30 days for 90 days were: $\mathrm{pH}$; total titratable acidity (ATT); Soluble Solids and Vitamin C; Microbiological analyzes were: total coliforms and Salmonella sp. Sensitivity analyzes of acceptability and intention to purchase were performed with 40 untrained tasters in two samples, one at $24 \pm 2^{\circ} \mathrm{C}$ and another at $15^{\circ} \mathrm{C}$. The results of the mixed nectar were: $19,8^{\circ} \mathrm{Brix}, \mathrm{pH} 2,83$, total titratable acidity $0,12 \%$ and vitamin $\mathrm{C} 139,75 \mathrm{mg} / 100 \mathrm{~mL}$ maintaining sanitary quality during the storage period. Mixed nectar obtained good acceptability in appearance, aroma and flavor attributes, and averages 7,$63 ; 7.90 ; 8.08$, respectively, at room temperature; at average refrigeration temperature $7.48 ; 7.60 ; 8.10$, respectively. The purchase intention of mixed nectar had no significant difference at room temperature (4.50) from the refrigerated one (4.58). The mixed nectar remained stable during storage, a good source of vitamin $\mathrm{C}$ with good acceptability and purchase intent.
\end{abstract}

Key-words: Nectar. Mixed Nectar. Açaí. Antille Cherry. Strawberry. 


\section{INTRODUÇÃO}

O consumo per capita de bebidas de frutas industrializadas prontas para o consumo (sucos, néctares e refrescos de frutas) quase dobrou no Brasil entre 2003 e 2008, conforme estimativas da Associação Brasileira das Indústrias de Bebidas Não Alcoólicas (ABIR). Em 2003, esse mercado era de 3,5 litros por brasileiro e atingiu 6,6 litros em 2008, segundo a Associação (HORTIFRUTI BRASIL, 2009).

Os néctares de frutas ganham espaço nesse mercado de bebidas justamente pela sua praticidade, palatabilidade e por apresentarem grande variedade de sabores. O Brasil ganha vantagem na elaboração desses produtos por ser destaque no agronegócio. Através de uma grande variedade de culturas produzidas em todo o país e em diversos climas, a fruticultura conquista resultados expressivos. O Brasil é o terceiro maior produtor de frutas do mundo, estando atrás apenas de China e Índia, o que mostra a relevância do setor para a economia brasileira (FAO, 2012 apud SEBRAE, 2015).

O Decreto $n^{\circ}$ 6.871, de 04 de junho de 2009 (BRASIL, 2009), define como néctar a bebida não fermentada, obtida da diluição em água potável da parte comestível do vegetal ou de seu extrato, adicionado de açúcares, destinada ao consumo direto; o néctar misto é a bebida obtida da diluição em água potável da mistura de partes comestíveis de vegetais, de seus extratos ou combinação de ambos, e adicionado de açúcares, destinada ao consumo direto.

Segundo dados fornecidos pela Mintel, no ano de 2013 foram lançadas 343 novas bebidas prontas para o consumo no mercado brasileiro: o néctar de fruta teve maior destaque, seguido por suco à base de frutas sem gás e suco integral (ABRE, 2014). Levando em consideração que o Brasil é um grande produtor de frutas tropicais, como o açaí, a acerola e o morango, é fácil elaborar novas bebidas no país.

$\mathrm{O}$ açaizeiro (Euterpe oleracea Martius) é uma palmeira tradicional da Amazônia, é destacada como sendo pertencente à divisão Magnoliophyta (= Angiospermae), classe Liliopsida Principes, família Arecaeae (= Palmae), estando incluído no gênero Euterpe (CAVALCANTE, 2010).

O açaí é considerado um alimento de elevado valor energético em decorrência de seu teor lipídico, como a presença dos ácidos graxos essenciais, Omega
- 6 e Omega - 9. Além disso, contém carboidratos, fibras, vitamina E, proteínas e minerais ( $\mathrm{Mn}, \mathrm{Fe}, \mathrm{Zn}$ $\mathrm{Cu}, \mathrm{Cr}$ ) (TONON et al., 2009; SANTOS et al., 2008). A acerola ou cereja das Antilhas (Malpighia glabra Linn), da família das Malpighiáceas, é proveniente das Antilhas, norte da América do Sul e América central. A cor avermelhada da acerola quando madura acontece devido à presença de antocianinas. $\mathrm{O}$ fruto possui maciez e suculência quando maduro, contêm um agradável sabor ácido característico (AGOSTINICOSTA et al., 2003).

A composição química, inclusive a distribuição de componentes do aroma, é dependente das espécies, condições ambientais e também do estágio de maturação da fruta. Esta fruta possui vários minerais, como cálcio, fósforo, potássio e ferro e elevado teor de vitaminas como $\mathrm{A}, \mathrm{B}_{1}, \mathrm{~B}_{2}, \mathrm{~B}_{3}$, antocianinas, carotenóides e, sobretudo, a vitamina $\mathrm{C}$ é uma de suas maiores fontes naturais. A ingestão de 2 a 4 unidades da fruta consegue suprir a quantidade média necessária de vitamina $C$ para um adulto saudável (GOMES et al. 2001; GONSALVES, 2002; VENDRAMINI; TRUGO, 2000).

O morangueiro é uma planta herbácea, rasteira e perene da família Rosaceae, ramificado por via vegetativa, através de estolhos. Geralmente a cultura desta espécie para produção de "frutos" é renovada anualmente. A parte comestível é na verdade o pseudofruto, que é proveniente do receptáculo floral que se torna polpudo e sucoso. Os frutos por assim dizer são pequenos aquênios, popularmente conhecidos como "sementes" (QUINATO et al., 2007).

O morango é uma fonte importante de algumas vitaminas como a $\mathrm{C}, \mathrm{A}, \mathrm{E}$ e folatos. É rico em pectina e outras fibras solúveis. Possui em sua composição também bioflavonóides, como a antocianina (de coloração vermelha) e o ácido elágico, substâncias que podem ajudar a evitar alguns tipos de câncer. (HERBÁRIO, 2005).

Se, por um lado, há uma crescente demanda do mercado ao consumir bebidas prontas, por outro, deve-se agregar valores nutricionais na elaboração de novos produtos e atender à expectativa do consumidor em associar a qualidade ao construir uma dieta e aproveitando a diversidade de sabores, aromas e cores que as matérias primas brasileiras podem lhe oferecer. Desta forma, o objetivo do presente trabalho é: elaborar um néctar misto à base de açaí, acerola e 
morango, mantendo o padrão de qualidade através das boas práticas de processamento e avaliar sua qualidade por meio de análises físico-químicas, sensoriais e microbiológicas.

\section{PROCEDIMENTOS METODOLÓGICOS}

\section{Delineamento do estudo}

O presente estudo é uma pesquisa do tipo descritiva, segundo seus objetivos; de levantamento, de acordo com os procedimentos técnicos utilizados; de laboratório, segundo as fontes de informação; com abordagem qualitativa e quantitativa, no qual foram realizadas as análises físico-químicas, sensoriais e microbiológicas de um néctar misto à base de açaí, acerola e morango.

\section{Matéria-prima}

A matéria prima analisada foi o produto denominado néctar misto elaborado a partir de três amostras de polpas congeladas de açaí, acerola e morango comercializadas em estabelecimento local em João Pessoa PB. O néctar misto produzido foi armazenado durante 90 dias em temperatura ambiente $\left(24 \pm 2^{\circ} \mathrm{C}\right)$ a partir do seu processamento (item 4.3) e avaliado a cada 30 dias.

\section{Processamento do néctar}

Utilizando as polpas comerciais, a formulação do néctar seguiu uma formulação padrão, com o uso da mistura das polpas de açaí, acerola e morango, acrescentadas de açúcar, água e ácido cítrico. As polpas foram selecionadas rigorosamente, para assegurar a qualidade do produto final. A formulação foi a mistura das polpas selecionadas, adequando-se os ingredientes em percentuais da seguinte forma: polpa de açaí $(60 \%)$, polpa de acerola (24\%), polpa de morango (16\%), em seguida, a formulação do néctar misto, composto por $45 \%$ da mistura das polpas de fruta, $42,4 \%$ de água potável, $12,4 \%$ de açúcar tipo cristal e $0,2 \%$ de ácido cítrico. O néctar misto foi acondicionado em garrafas de vidro de $200 \mathrm{ml}$ e $500 \mathrm{ml}$ e recravadas com tampas de metal e plástico, em seguida pasteurizado em temperatura de $60^{\circ} \mathrm{C}$ durante 30 minutos. Logo após, foi armazenado em temperatura ambiente $\left(24 \pm 2{ }^{\circ} \mathrm{C}\right)$ durante 90 dias. $\mathrm{O}$ processamento do néctar seguiu o fluxograma apresentado na Figura 1 e 2.
Figura 1: Fluxograma do processamento de néctar misto a base de açaí, acerola e morango.

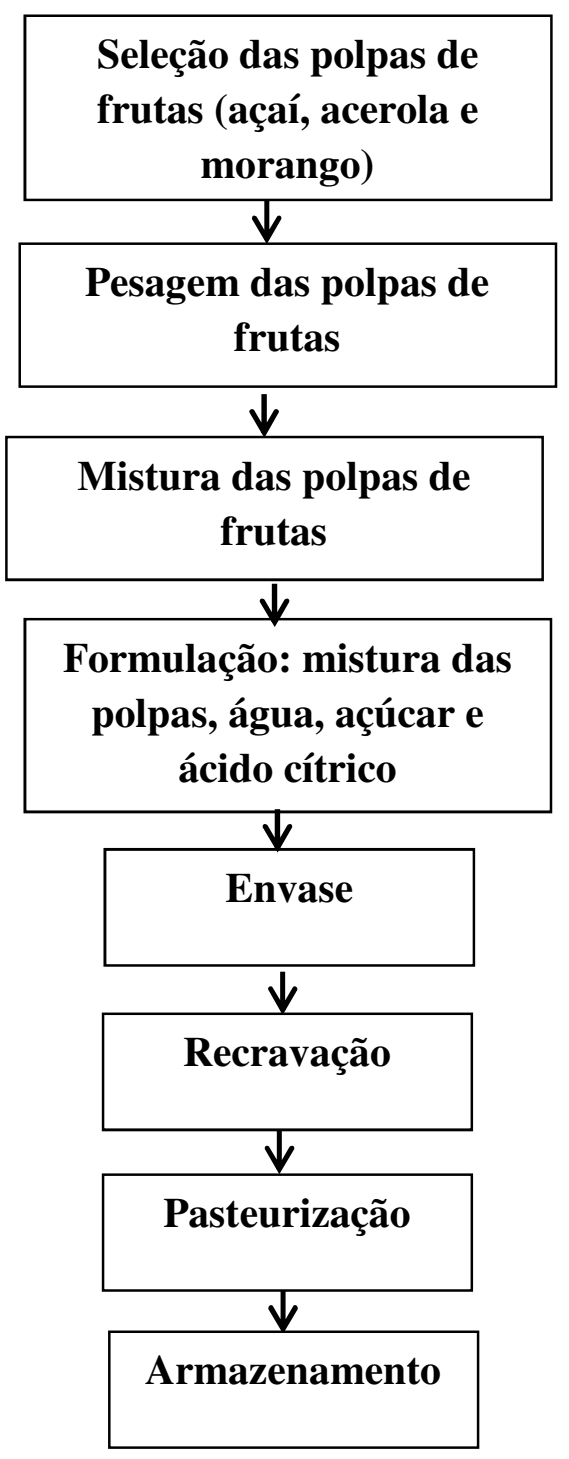


Figura 2: Fluxograma ilustrativo do processamento do néctar misto a base de açaí, acerola e morango.

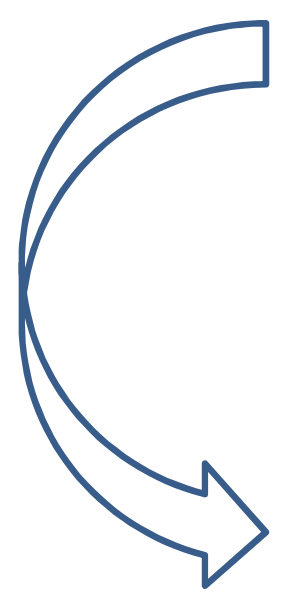

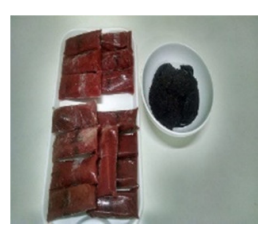

Seleção das polpas de frutas (açaí, acerola e morango)
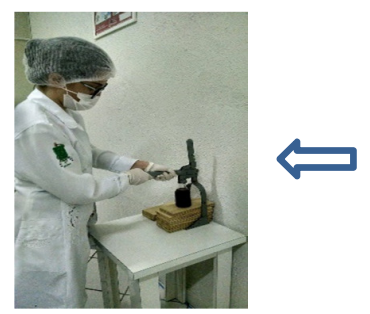

Recravação
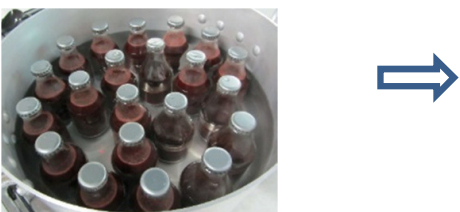

Pasteurização
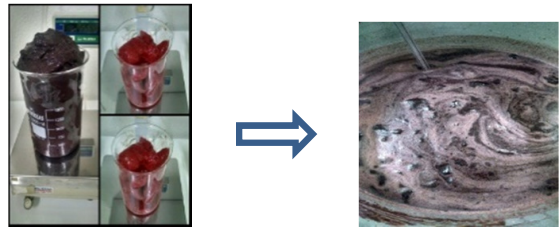

Pesagem das polpas de frutas
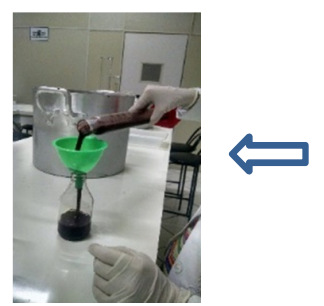

Mistura das polpas de frutas
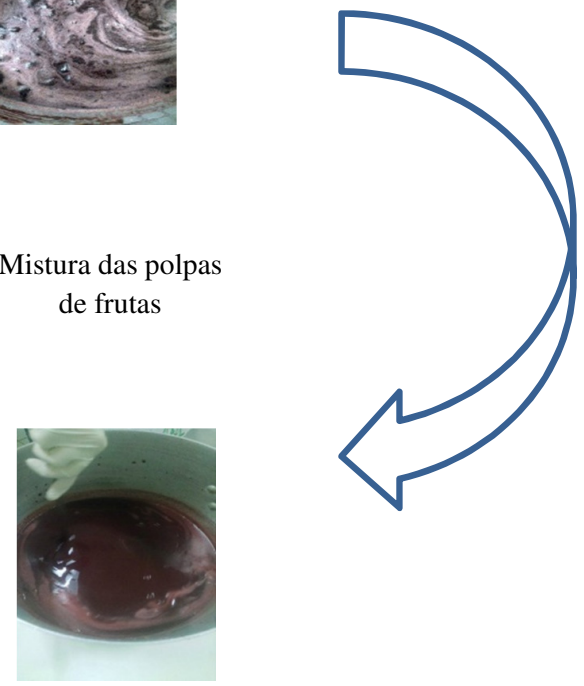

Formulação: mistura das polpas, água, açúcar e ácido cítrico

\section{Caracterização do local, período e dos participantes da pesquisa}

A produção do néctar misto à base de açaí, acerola e morango foi desenvolvida no laboratório de Tecnologia de Alimentos da Faculdade de Ciências Médicas, na cidade de João Pessoa - PB, do mês de fevereiro 2017, conforme a formulação apresentada no item 4.3. Para a avaliação sensorial do néctar que ocorreu no mês de março de 2017, foram selecionados os provadores que eram os estudantes do curso de graduação em Nutrição da Faculdade de Ciências Médicas da Paraíba, do $1^{\circ}$ ao $7^{\circ}$ período, não treinados e voluntários. Tendo em vista a impossibilidade de avaliar todos os estudantes (cerca de 100 alunos), a quantidade de provadores será estimada em $40 \%$ da população, perfazendo um total de 100 alunos. Foi realizado um sorteio aleatório entre os estudantes das turmas selecionadas para o estudo.

A amostra foi determinada seguindo os seguintes critérios:

Critérios de inclusão: indivíduos das turmas selecionadas para a pesquisa, de ambos os gêneros, e que aceitaram participar da pesquisa e assinar o Termo de Consentimento Livre e Esclarecido (TCLE); 
Critérios de exclusão: indivíduos que não aceitaram participar da pesquisa.

\section{Análises físico-químicas}

As análises físico-químicas foram realizadas com o néctar misto elaborado a partir de sua formulação, seguida a cada 30 dias até o prazo de 90 dias, em triplicata.

\section{Determinação de $\mathrm{pH}$}

$\mathrm{O} \mathrm{pH}$ foi determinado pelo processo potenciométrico, utilizando um pHmetro da marca PHTEK, modelo PHS-3B. O aparelho foi calibrado com solução tampão de pH 4,0 e 7,0, e em seguida foi tomada a leitura direta do $\mathrm{pH}$ com imersão do eletrodo em um béquer contendo a amostra e seguindo a metodologia do Instituto Adolfo Lutz (1985).

\section{Determinação de Acidez Total Titulável (ATT)}

Para se obter a acidez total titulável (ATT), foram utilizados $10 \mathrm{ml}$ do néctar, junto a três gotas de fenolftaleína e titulação com $\mathrm{NaOH}$ a $0,1 \mathrm{~N}$ padronizado e o resultado expresso em porcentagem do ácido predominante da fruta (ácido cítrico), de acordo com a técnica utilizada pelo Instituto Adolfo Lutz (1985).

\section{Determinação de Sólidos Solúveis ('Brix)}

Os valores de sólidos solúveis totais foram determinados pela leitura direta, utilizando-se um refratômetro da marca Quimis, modelo Q767, com escala de 0 - $32{ }^{\circ}$ Brix e seus resultados expressos em ${ }^{\circ}$ Brix corrigindo quanto a temperatura, seguindo as normas do Instituto Adolfo Lutz (1985).

\section{Determinação de Vitamina $C$}

A análise de vitamina $\mathrm{C}$ foi realizada no Laboratório de Tecnologia de Alimentos do Centro de Tecnologia da Universidade Federal da Paraíba (CT/UFPB), utilizando o método Titulométrico com o uso de 2,6-diclorofenolindofenol (DFI), segundo o Instituto Adolfo Lutz (1985). Nesse processo usou-se $10 \mathrm{ml}$ de néctar misto. Em seguida foi agitada, filtrada e titulada uma alíquota de $10 \mathrm{ml}$ do filtrado, conforme descrito na padronização da solução de Tillmans. Foi feito um branco constituído de $10 \mathrm{ml}$ da solução ácida e com volume de água igual ao da solução do corante gasto na titulação da amostra e em seguida foi titulado.
Os íons $\mathrm{Fe}^{2+}, \mathrm{Sn}^{2+}$ e $\mathrm{Cu}^{2+}$ presentes na amostra a ser analisada, interferem neste método. Neste caso, previamente à determinação da vitamina $\mathrm{C}$ verificou-se $\mathrm{a}$ presença dos interferentes, procedendo como descrito: adicionando duas gotas da solução de azul de metileno $0,05 \%$ a $10 \mathrm{ml}$ da mistura $1: 1$ constituída da amostra de néctar e do reagente ácido

\section{Análises Microbiológicas}

As análises microbiológicas foram realizadas no Laboratório de Microbiologia de Alimentos do Centro de Tecnologia da Universidade Federal da Paraíba (UFPB), e constaram das análises a cada 30 dias durante um período de 90 dias da formulação selecionada. Os grupos pesquisados eram os coliformes a $45^{\circ} \mathrm{C}$, e Salmonella sp, realizadas todas em triplicata, de acordo com a Resolução RDC n ${ }^{\circ} 1 \times 2$, de 02 de janeiro de 2001, que estabelece padrões para sucos pasteurizados (BRASIL, 2001).

No que tange à análise do grupo coliformes, foi realizada a homogeneização da amostra em um frasco contendo $225 \mathrm{ml}$ do diluente (água peptonada $0,1 \%$ ), transferindo a amostra homogeneizada para os demais tubos de diluição. Para o teste presuntivo, foi transferido $1,0 \mathrm{ml}$ de cada diluição para os respectivos tubos de Caldo LST e posteriormente incubado em estufa a $35^{\circ} \mathrm{C} / 24 \mathrm{~h}$. Por sua vez, os tubos positivos de LST (com produção de gás) foram transferidos com auxílio de uma alça metálica para os tubos contendo Caldo BVB (confirmativo para Coliforme total) e Caldo EC (confirmativo para Coliforme Fecal). Os tubos de BVB foram incubados em estufa a $35^{\circ} \mathrm{C} / 24 \mathrm{~h}$ e os tubos de EC serão levados ao banho-maria a $45,5^{\circ} \mathrm{C} / 24 \mathrm{~h}$ (BRASIL, 2003).

Com relação à determinação e Salmonella sp foi realizada por meio de etapa inicial de pré-enriquecimento da amostra, utilizando-se caldo lactosado, com incubação a $35^{\circ} \mathrm{C}$ por 24 horas, seguido por etapa de enriquecimento seletivo com caldo Tetrationato (TT) e caldo Rappaport-Vassilidis Modificado (RV). Em seguida, alíquotas dos caldos de enriquecimento seletivo foram inoculadas em ágar Bismuto Sulfito, ágar entérico Hektoen e ágar Xilose Lisina Desoxicolato, e o resultado foi descrito em ausência/presença em $25 \mathrm{~g}$ ou ml (BRASIL, 2003). 


\section{Análises Sensoriais}

Realizamos uma análise sensorial do néctar misto à base de açaí, acerola e morango para avaliarmos a sua aceitabilidade e intenção de compra utilizando aproximadamente $50 \mathrm{ml}$ do néctar recém-processado, codificado e sem qualquer identificação, apresentando-o a temperatura ambiente e a temperatura de refrigeração $\left(\sim 15^{\circ} \mathrm{C}\right)$ para cada avaliador. Para julgamento dos atributos aparência, aroma e sabor, e intenção de compra, os avaliadores registraram as suas notas de aceitação em um formulário que foi entregue aos mesmos no momento da avaliação sensorial.

O teste de aceitabilidade e intenção de compra foi adaptado para duas amostras codificadas, através da ficha apresentada por Souza e Menezes (2006), com o uso de escala hedônica proposta por Hernandes et al. (2007), com a nota dos atributos de 1 a 9, sendo o valor 1 para o termo "desgostei extremamente" e o valor 9 para o termo "gostei extremamente". Para o limite inferior da média de aceitação do produto, foi estabelecido o valor de 5. Para a intenção de compra, foi utilizada uma escala estruturada de cinco pontos, variando de "certamente compraria" a "certamente não compraria" (NUNES et al., 2006). No teste de aceitabilidade e intenção de compra, foi disponibilizado espaço para os provadores expressarem suas opiniões livremente.

\section{Questões éticas}

O presente estudo foi submetido à revisão do Comitê de Ética em Pesquisa da Faculdade de Ciências Médicas da Paraíba, durante o mês de dezembro de 2016, através da Plataforma Brasil, de acordo com as exigências da Comissão Nacional de Ética em Pesquisa (CONEP) e do Conselho Nacional de Saúde, através da sua Resolução $n^{\circ} 466 / 12$, que trata de pesquisas envolvendo seres humanos. Os participantes foram devidamente esclarecidos sobre os objetivos e os métodos a serem utilizados na pesquisa, além dos seus direitos como participantes. Assinaram o Termo de Consentimento Livre e Esclarecido (TCLE) e receberam uma via deste termo. O termo de anuência e de corresponsabilidade permitiu a autorização formal da instituição coparticipante. A folha de rosto da CONEP (Comissão Nacional de Ética em Pesquisa) foi assinada por um representante legal da Faculdade de Ciências Médicas da Paraíba, a coordenadora do curso de Nutrição.

Para esta pesquisa não foram previstos riscos à saúde física, mental e espiritual; podendo haver riscos de algum constrangimento, porém, estes foram evitados, pois a pesquisadora acadêmica, bem treinada, avaliou quem participou com todo cuidado e respeito. Caso tivesse ocorrido algum dano físico ou psicológico, o (a) participante teria sido encaminhado (a) ao setor competente e assistido por profissionais da área, da Fundação Otacílio Gama e da Policlínica da Faculdade de Ciências Médicas da Paraíba.

\section{Coleta de Dados}

Após a aprovação do Comitê de Ética em Pesquisa da Faculdade de Ciências Médicas da Paraíba, os dados foram coletados durante o mês de fevereiro até junho de 2017. Os resultados das análises físico-químicas foram obtidos e calculadas suas médias para avaliação do comportamento da estabilidade do néctar misto à base de açaí, acerola e morango. Os resultados das análises microbiológicas foram obtidos para avaliação da qualidade do produto e se ele estava propício para o consumo humano. Quanto à sua aceitabilidade e intenção de compra, estes aspectos foram avaliados através das análises sensoriais.

\section{Tratamento de Dados}

Os resultados foram avaliados através de análises estatísticas e pela utilização do programa Statistical Package for the Social Sciences (SPSS) versão 21, para determinação da análise de variação em nível de $5 \%$, e a frequência através de valores relativos (porcentagens).

\section{RESULTADOS E DISCUSSÕES}

\section{Análises Físico-Químicas}

No dia do processamento do néctar misto à base de açaí, acerola e morango foram feitas as análises físico-químicas do produto antes e depois da pasteurização, para verificar as possíveis perdas de Vitamina $\mathrm{C}$ e a mudança de outras características. Os resultados estão apresentados na Tabela 1. Observando os resultados dos teores de vitamina $\mathrm{C}$ constatou-se que ocorreu diminuição dos valores no néctar pasteurizado, em aproximadamente $10 \%$. 
Tabela 1: Análises físico-químicas de néctar misto à base de açaí, acerola e morango no dia do processamento.

\begin{tabular}{|c|c|c|c|c|c|}
\hline \multirow[b]{2}{*}{ Amostras } & \multicolumn{3}{|c|}{ Análises } & \multirow[b]{2}{*}{$\begin{array}{c}\text { Vitamina C } \\
(\mathrm{mg} / 100 \mathrm{~g})\end{array}$} & \multirow[b]{2}{*}{$\begin{array}{l}\text { SS/ } \\
\text { ATT }\end{array}$} \\
\hline & $\begin{array}{c}\text { Sólidos } \\
\text { Solúveis } \\
\left({ }^{\circ} \mathrm{Bx}\right)\end{array}$ & $\begin{array}{c}\text { ATT } \\
(\mathrm{g} / \mathbf{1 0 0 g})^{1}\end{array}$ & pH & & \\
\hline $\begin{array}{l}\text { Néctar misto } \\
\text { sem } \\
\text { pasteurização }\end{array}$ & 19,8 & 0,13 & 2,97 & 149,33 & 152,3 \\
\hline $\begin{array}{l}\text { Néctar misto } \\
\text { Pasteurizado }\end{array}$ & 19,8 & 0,13 & 2,79 & 134,35 & 152,3 \\
\hline
\end{tabular}

O processo de conservação mais utilizado para sucos de fruta é a pasteurização, que utiliza temperaturas inferiores a $100^{\circ} \mathrm{C}$, com o objetivo de destruir microrganismos deteriorantes e inativar enzimas. Como a pectinaesterase é mais termorresistente que os microrganismos, um tratamento térmico mais intenso é necessário para inativar enzimas do que para destruir microrganismos (EVANGELISTA, 2001).

$A$ perda de vitamina $C$ no néctar misto à base de açaí, acerola e morango foi maior, se comparado com o estudo realizado por Lo Scalzo et al. (2004), em que observaram o conteúdo de ácido ascórbico de suco de laranja antes e após a pasteurização. O teor de ácido ascórbico no suco de laranja fresco foi de 44,27 $\mathrm{mg} / 100 \mathrm{~mL}$ e, após pasteurização, de 42,69 mg/100mL, tendo sido retido $96 \%$ do conteúdo inicial. Entretanto, neste estudo, a perda foi menor quando comparada ao estudo realizado por Fernandes et al. (2007) com suco de goiaba: neste, a taxa perdida de vitamina $\mathrm{C}$ foi de 43,46 mg/100 mL após a pasteurização; ainda, uma redução de $12 \%$ foi observada após o processamento térmico do suco.

Apesar das perdas durante o processamento, o produto, após pasteurização, apresentou teor bastante elevado de vitamina $\mathrm{C}$, e o consumo de $100 \mathrm{~mL}$ do néctar misto supriria aproximadamente $149 \%$ da recomendação diária para um homem adulto saudável, de acordo com o Institute of Medicine (2000), que seria $90 \mathrm{mg}$.

Durante o armazenamento foram realizadas as análises físico-químicas visando a determinar a estabilidade do néctar misto à base de açaí, acerola e morango. Na Tabela 2 estão os resultados das análises ao longo do período de armazenamento.

O valor mínimo permitido de sólidos solúveis em alguns néctares (abacaxi, acerola, cajá, maracujá) é de $11^{\circ}$ Brix. A formulação em questão atende a esse valor mínimo solicitado e permaneceu em uma média de $19,8^{\circ}$ Brix durante todo o período de armazenamento (BRASIL, 2003). No trabalho elaborado por Chim et al. (2013) com néctar de acerola, após o processamento do mesmo, foi encontrado um teor de $15,1^{\circ}$ Brix. Morzelle et al. (2011), em estudo com néctar misto de maracujá e araticum, obteve para as duas formulações estudadas $14^{\circ}$ Brix e $16^{\circ}$ Brix. No trabalho de Perfeito; Corrêa e Peixoto (2017) com néctar misto de cagaita e mangaba, foram encontradas nas três formulações estudadas $19,5^{\circ}$ Brix, $17^{\circ}$ Brix e $18^{\circ}$ Brix, respectivamente.

A acidez teve uma média de $0,12 \%$ de ácido cítrico durante todo o período de armazenamento, bem baixo se comparado a outros estudos. Souza et al. (2012) obteve 0,27\% de ácido cítrico em néctar de kiwi. Morzelle et al. (2011) em estudo com néctar misto de maracujá e araticum, obteve para as duas formulações estudadas 0,57 e $0,46 \%$ de ácido cítrico.

$\mathrm{O}$ pH permaneceu em uma média de 2,83 , durante todo o período de armazenamento. Assumpção et al. (2013) em estudo com néctar misto de mangaba e cagaita obteve para as duas formulações estudadas $\mathrm{pH}$ de 3,27 e 3,29. No trabalho de Damiani et al. (2011) com néctar misto de cajá-manga com hortelã, obteve-se um pH de 2,72. Morzelle et al. (2011) em estudo com néctar misto de maracujá e araticum, obteve para as duas formulações estudadas pH de 3,3 e 3,6. Segundo Paltrinieri e Figuerola (1997) o pH final de néctares deve sempre estar abaixo de 4,0, portanto, o valor encontrado na formulação analisada está de acordo com a literatura.

Tabela 2: Análises físico-químicas de néctar misto à base de açaí, acerola e morango durante o período de armazenamento.

\begin{tabular}{l|c|c|c|c}
\hline \multirow{2}{*}{ Análises } & \multicolumn{3}{|c|}{ Período de } & \\
\cline { 2 - 5 } & armazenamento (dias) & \\
\hline Sólidos Solúveis ( $\left.{ }^{\circ} \mathrm{Bx}\right)$ & 19,8 & 19,8 & 19,8 & 19,8 \\
\hline ATT (g/100g) & 0,13 & 0,10 & 0,12 & 0,11 \\
\hline Ph & 2,79 & 2,85 & 2,78 & 2,89 \\
\hline Vitamina C (mg/100g) & 134,35 & 166,61 & 134,47 & \\
\hline SS/ATT & 152,3 & 198,0 & 165,0 & 180 \\
\hline
\end{tabular}


Faraoni et al. (2011) desenvolveram sucos mistos de manga, goiaba e acerola com diferentes formulações e obtiveram a média geral de ácido ascórbico em 45,90mg/100mL. Souza (2006) determinou teores de vitamina $\mathrm{C}$ em néctares com diferentes proporções de polpa de caju, acerola e manga variando de 48 a 56 $\mathrm{mg} / 100 \mathrm{~mL}$. Pinheiro (2008) encontrou valores para as onze formulações de néctar misto à base de caju e açaí entre 10 e $50 \mathrm{mg} / 100 \mathrm{~mL}$. A média ao longo do armazenamento desta formulação foi de $139,75 \mathrm{mg} / 100 \mathrm{~mL}$. O que se observa é que, em cada formulação de néctar misto, a contribuição no teor de vitamina $\mathrm{C}$ depende das matérias-primas adicionadas e suas quantidades.

\section{Análises Microbiológicas}

A qualidade microbiológica (Tabela 3) demostrou que o processo térmico do néctar misto à base de açaí, acerola e morango foi suficiente para evitar crescimento microbiano e mantê-lo em condições sanitárias durante o período de armazenamento. O produto, portanto, se apresentou de acordo com a Resolução $\mathrm{RDC}^{\circ}$ 12, de 02 de janeiro de 2001 (BRASIL, 2001), que estabelece padrões para sucos pasteurizados; ela indica os valores para coliformes a $45^{\circ} \mathrm{C}<3 \mathrm{NMP} / \mathrm{mL}$ e ausência de Salmonella sp.

Apesar de o processo térmico ter sido suficiente para a conservação do néctar misto à base de açaí, acerola e morango durante todo o período de armazenamento, vale ressaltar que o uso da refrigeração auxilia a importância para a conservação deste tipo de produto. Mattieto et al. (2007) no desenvolvimento de néctar misto de umbu e cajá, observaram o aparecimento de bolores, leveduras e bactérias mesófilas ao final de 75 dias de armazenamento em temperatura ambiente, apesar do baixo $\mathrm{pH}$ da formulação.
Tabela 3: Análises Microbiológicas do néctar misto à base de açaí, acerola e morango durante o período de armazenamento

\begin{tabular}{l|c|c|c|c}
\hline \multirow{2}{*}{ Análises } & \multicolumn{4}{|c}{ Período de armazenamento (dias) } \\
\cline { 2 - 5 } & $\mathbf{1}^{\mathbf{0}}$ & $\mathbf{3 0}^{\mathbf{0}}$ & $\mathbf{6 0}^{\mathbf{0}}$ & $\mathbf{9 0}^{\mathbf{0}}$ \\
\hline $\begin{array}{l}\text { Coliformes à } 45^{\circ} \\
\mathrm{C} / \mathrm{mL}\end{array}$ & 0,0 & 0,0 & 0,0 & 0,0 \\
\hline $\begin{array}{l}\text { Salmonella } \mathrm{sp} / 25 \\
\mathrm{~mL}\end{array}$ & Ausência & Ausência & Ausência & Ausência \\
\hline
\end{tabular}

\section{Análises Sensoriais}

Os resultados da análise sensorial estão apresentados nas Tabelas 4 e 5. No atributo Aparência, a amostra em temperatura ambiente obteve a maior avaliação em "Gostei Moderadamente" e a amostra em temperatura de refrigeração em "Gostei Muito"; porém, no contexto geral, pode-se avaliar que a amostra em temperatura ambiente teve um maior desempenho. Portanto, a amostra apresentada em temperatura ambiente obteve um total de $90 \%$ de preferência, enquanto a amostra em temperatura de refrigeração atingiu $82,5 \%$, mas esta disparidade não se mostra significativa $(\mathrm{p}>0,05)$.

No atributo Aroma, a amostra em temperatura ambiente obteve a maior votação em "Gostei Muito" e a amostra em temperatura de refrigeração, por sua vez, destacou-se em "Gostei Moderadamente". A Tabela 5 confirma que a amostra em temperatura ambiente obteve realmente o melhor julgamento entre as duas amostras, nesse caso, sem significância ( $p>0,05)$. A amostra em temperatura ambiente obteve uma melhor avaliação: atingiu 97,5\% de preferência do aroma em relação à amostra em temperatura de refrigeração que foi de $90,0 \%$, mas esta diferença não é significativa $(\mathrm{p}>0,05)$.

Tabela 4: Teste Qui-Quadrado e valores de p para as variáveis do teste de aceitabilidade do néctar misto à base de açaí, acerola e morango em duas temperaturas.

\begin{tabular}{|c|c|c|c|c|c|c|c|c|c|c|c|c|c|}
\hline \multirow[t]{2}{*}{ Variáveis } & & \multicolumn{2}{|c|}{ Indiferente } & \multicolumn{2}{|c|}{$\begin{array}{c}\text { Gostei } \\
\text { Lig. }\end{array}$} & \multicolumn{2}{|c|}{$\begin{array}{l}\text { Gostei } \\
\text { Mod. }\end{array}$} & \multicolumn{2}{|c|}{$\begin{array}{l}\text { Gostei } \\
\text { Muito }\end{array}$} & \multicolumn{2}{|c|}{$\begin{array}{c}\text { Gostei } \\
\text { Ext. }\end{array}$} & \multirow[t]{2}{*}{$\chi^{2}$} & \multirow[t]{2}{*}{$p$} \\
\hline & & $\mathrm{N}$ & $\%$ & $\mathrm{~N}$ & $\%$ & $\mathrm{~N}$ & $\%$ & $\mathrm{~N}$ & $\%$ & $\mathrm{~N}$ & $\%$ & & \\
\hline \multirow[t]{2}{*}{ Aparência } & $457 *$ & 2 & 5,0 & 2 & 5,0 & 16 & 40,0 & 9 & 22,5 & 11 & 27,5 & \multirow{2}{*}{3,35} & \multirow{2}{*}{0,50} \\
\hline & $458 * *$ & 4 & 10,0 & 3 & 7,5 & 11 & 27,5 & 14 & 35,0 & 8 & 20,0 & & \\
\hline \multirow[t]{2}{*}{ Aroma } & 457 & 1 & 2,5 & 0 & 0,0 & 11 & 27,5 & 18 & 45,0 & 10 & 25,0 & \multirow{2}{*}{4,30} & \multirow{2}{*}{0,37} \\
\hline & 458 & 3 & 7,5 & 1 & 2,5 & 15 & 37,5 & 11 & 27,5 & 10 & 25,0 & & \\
\hline \multirow[t]{2}{*}{ Sabor } & 457 & & 0,0 & 1 & 2,5 & 8 & 20,0 & 18 & 45,0 & 13 & 32,5 & \multirow{2}{*}{1,65} & \multirow{2}{*}{0,80} \\
\hline & 458 & 1 & 2,5 & 1 & 2,5 & 7 & 17,5 & 15 & 37,5 & 16 & 40,0 & & \\
\hline
\end{tabular}

\footnotetext{
* Temperatura ambiente; ** Temperatura de refrigeração.
} 
Tabela 5: Teste $t$ do teste de aceitabilidade do néctar misto à base de açaí, acerola e morango, em temperatura ambiente e de refrigeração.

\begin{tabular}{l|c|c|c|c|c|c|c}
\hline Variáveis & \multicolumn{2}{|c|}{$457 *$} & \multicolumn{2}{|c|}{$\mathbf{4 5 8}^{* *}$} & & & \\
\hline & M & DP & M & DP & T & gl & $p$ \\
\hline Aparência & 7,63 & 1,10 & 7,48 & 1,20 & 0,13 & 78 & 0,56 \\
\hline Aroma & 7,90 & 0,87 & 7,60 & 1,13 & 4,22 & 78 & 0,19 \\
\hline Sabor & 8,08 & 0,80 & 8,10 & 0,96 & 0,87 & 78 & 0,89 \\
\hline
\end{tabular}

* Temperatura ambiente; ** Temperatura de refrigeração.

No atributo Sabor, a amostra em temperatura ambiente obteve a maior votação em "Gostei Muito", enquanto a amostra em temperatura de refrigeração, em "Gostei Extremamente. A Tabela 5 confirma exatamente que a amostra em temperatura de refrigeração obteve o melhor julgamento entre as duas amostras, porém, sem significância ( $\mathrm{p}>0,05)$. Houve uma melhor avaliação para a amostra em temperatura de refrigeração com um total de $97,5 \%$ e $95 \%$ para a amostra em temperatura ambiente.

Neste estudo o néctar misto à base de açaí, acerola e morango atingiu uma avaliação de boa aceitação (Tabela 5) quanto à aparência, aroma e sabor, e cujas médias foram 7,63, 7,90 e 8,08, respectivamente para a amostra em temperatura ambiente e, de 7,48, 7,60 8,10 , para a amostra em temperatura de refrigeração, entretanto, não houve significância para nenhuma média dos atributos avaliados ( $p>0,05)$.

Há estudos que evidenciam a interferência da temperatura nas percepções dos sabores dos alimentos; a redução da temperatura potencializa o sabor azedo, embora uma parcela menor de pessoas perceba também o salgado. Já o aumento é percebido, momentaneamente, como uma sensação de doçura. Foi demonstrado que essas sensações são provenientes da estimulação direta de receptores ou de canais iônicos nas membranas celulares. Isso significa, por exemplo, que comer um mesmo chocolate em diferentes temperaturas gera experiências gustativas distintas. Quanto mais quente estiver o chocolate, mais doce ele parecerá (FABER, 2006).

Apesar de não ter ocorrido preferência significativa entre as amostras por parte dos provadores, vale ressaltar os comentários feitos pelos mesmos no campo de observações sobre o aspecto global, no qual quem preferiu a amostra em temperatura ambiente foi por julgar mais doce, e quem preferiu a amostra em temperatura de refrigeração pelo mesmo motivo.
Na Tabela 6 estão evidentes os resultados da avaliação de intenção de compra para as duas amostras: ambas tiveram maiores notas para "Certamente Compraria", $60 \%$, para a amostra em temperatura ambiente e $67,5 \%$ para a amostra em temperatura de refrigeração.

Tabela 6: Teste Qui-Quadrado da intenção compra de néctar misto à base de açaí, acerola e morango, em temperatura ambiente e de refrigeração.

\begin{tabular}{l|l|l|l|l|l|l|l|l}
\hline Amostras & \multicolumn{2}{|l|}{$\begin{array}{l}\text { Certam. } \\
\text { Compraria }\end{array}$} & \multicolumn{2}{|l|}{$\begin{array}{l}\text { Possiv. } \\
\text { Compraria }\end{array}$} & \multicolumn{2}{l|}{$\begin{array}{l}\text { Talvez } \\
\text { comprasse } \\
\text { ou não }\end{array}$} & $\chi^{2}$ & $P$ \\
\hline & $\mathrm{N}$ & $\%$ & $\mathrm{~N}$ & $\%$ & $\mathrm{~N}$ & $\%$ & & \multirow{2}{*}{0,74} \\
\hline $\mathbf{4 5 7 *}$ & 24 & $60,0 \%$ & 12 & $30,0 \%$ & 4 & $10,0 \%$ & 0,74 \\
\hline $\mathbf{4 5 8 * *}$ & 27 & $67,5 \%$ & 9 & $22,5 \%$ & 4 & $10,0 \%$ & & \\
\hline
\end{tabular}

*Temperatura ambiente; ** Temperatura de refrigeração.

A amostra em temperatura de refrigeração obteve a maior média $(4,58)$ em relação a amostra em temperatura ambiente $(4,50)$, porém não foi significativa ( $>00,05)$, como demostra a Tabela 7 .

Tabela 7 - Teste t da intenção de compra de néctar misto à base de açaí, acerola e morango, em temperatura ambiente e de refrigeração.

\begin{tabular}{c|c|c|c|c|c}
\hline Amostras & M & DP & T & gl & $P$ \\
\hline $\mathbf{4 5 7}^{*}$ & 4,50 & 0,679 & \multirow{2}{*}{0,49} & \multirow{2}{*}{78} & \multirow{2}{*}{0,62} \\
\cline { 1 - 3 } $\mathbf{4 5 8 * *}$ & 4,58 & 0,675 & & & \\
\hline
\end{tabular}

* Temperatura ambiente; ** Temperatura de refrigeração.

\section{CONCLUSÃO}

Com os dados obtidos pode-se concluir que:

O néctar misto à base de açaí, acerola e morango, na formulação estudada, apresentou características físico-químicas estáveis no período de armazenamento de 0 a 90 dias, com a acidez variando de $0,13 \%$ à $0,11 \%$ de ácido cítrico, $\mathrm{pH}$ variando de 2,79 à 2,89 , sólidos solúveis de $19,8^{\circ}$ Brix sem variação, e vitamina $\mathrm{C}$ de 134,35 à $123,58 \mathrm{mg} / 100 \mathrm{~mL}$.

O produto formulado apresenta comportamento estável no período de 90 dias de armazenamento quanto às análises microbiológicas com ausência de Salmonella sp. e contagem total de coliformes. Nas análises sensoriais, os 40 provadores consideraram o néctar misto à base de açaí, acerola e morango de aparência, aroma e sabor bastante aceitáveis e demonstraram interesse em adquirir o produto caso fosse comercializado. 
$\mathrm{Na}$ avaliação dos provadores do néctar misto a base de açaí, acerola e morango em temperatura ambiente $\left(24^{\circ} \mathrm{C} \pm 2\right)$ e de refrigeração $\left(15^{\circ} \mathrm{C}\right)$ não houve diferença significativa em suas preferências.

\section{REFERÊNCIAS}

ASSOCIAÇÃO BRASILEIRA DE EMBALAGEM ABRE. 2014. Disponível em: <http://www.abre.org.br/ noticias/consumo-de-sucos-prontos-cresce-125-em-umano/>. Acesso em: 20 ago. 2016.

AGOSTINI-COSTA, T. da S.; ABREU, L. N. de; ROSSETTI, A. G. Efeito do congelamento e do tempo de estocagem da polpa de acerola sobre o teor, de carotenóides. Revista Brasileira de Fruticultura, Jaboticabal, v. 25, n. 1, p. 56-58, 2003.

ASSUMPÇÃO, C. F.; BACHIEGA, P.; SANTANA, A. T. M. C.; MORZELLE, M. C.; BOAS, B. M. V.; SOUZA, E. C. Néctar misto de mangaba (Hancoria speciosa Gomes) e cagaita (Eugenia dysenterica): perfil sensorial e características físico-químicas. Revista Brasileira de Produtos Agroindustriais, Campina Grande, v.15, n.3, p.219-224, 2013.

BRASIL. Agência nacional de Vigilância Sanitária. Regulamento Técnico sobre Padrões Microbiológicos para Alimentos. Resolução RDC $\mathbf{n}^{\mathbf{0}} \mathbf{1 2}$ de $\mathbf{0 2}$ de janeiro de 2001. Diário Oficial da União, 2001.

BRASIL. Decreto n. ${ }^{\circ}$ 6.871, de 4 de junho de 2009, Regulamenta a Lei no 8.918 , de 14 de julho de 1994, que dispõe sobre a padronização, a classificação, o registro, a inspeção, a produção e a fiscalização de bebidas. Diário Oficial da República Federativa do Brasil. Brasília, DF. Disponível em: < http://www.planalto.gov.br/ccivil_03/ Ato2007-2010/2009/Decreto/D6871.htm>. Acesso em: 24 ago. 2016.

BRASIL, Ministério da Agricultura, Pecuária e Abastecimento. Secretaria de Defesa Agropecuária. Instrução Normativa $\mathbf{n}^{\mathbf{0}}$ 62, de 26 de agosto de 2003. Diário Oficial da União de 18/09/2003.

BRASIL, Ministério da Agricultura, Pecuária e Abastecimento. Secretaria de Defesa Agropecuária. Instrução Normativa $\mathbf{N}^{0}$ 12, de 4 de setembro de 2003. Diário Oficial da União de 09/09/2003.

CAVAlCANTE, P. B. Frutas Comestíveis na Amazônia. 7. ed. Belém: Museu Paraense Emílio Goeldi, 2010.

CHIM, J. F.; ZAMBIAZI, R. C.; RODRIGUES, R. S. Estabilidade da vitamina $\mathrm{c}$ em néctar de acerola sob diferentes condições de armazenamento. Revista Brasileira de Produtos Agroindustriais, Campina Grande, v.15, n.4, p.321-327, 2013
DAMIANI, C.; SILVA, F. A.; AMORIM, C. C. M.; SILVA, S. T. P.; BASTOS, I. M.; ASQUIERI, E. R.; VERA, R. Néctar misto de cajá-manga com hortelã: caracterização química, microbiológica e sensorial. Revista Brasileira de Produtos Agroindustriais, Campina Grande, v.13, n.3, p.299-307, 2011.

FABER, J. Avanços na compreensão do paladar. Rev. Dent. Press Ortodon. Ortop. Facial. vol.11, n.1 Maringá jan. / fev. 2006.

FARAONI, A. S.; RAMOS, A. M.; GUEDES, D. B.; OLIVEIRA, A. N.; LIMA, T. H. S. F. L. SOUSA, P. H. M. Desenvolvimento de um suco misto de manga, goiaba e acerola utilizando delineamento de misturas. Ciência Rural, Santa Maria, 2012.

FERNANDES, A. G.; MAIA, G. A.; SOUSA, P. H.; COSTA, J. M.; FIGUEIREDO, R. W.; PRADO, G. M. Comparação dos teores em vitamina $\mathrm{C}$, carotenóides totais, antocianinas totais e fenólicos totais do suco tropical de goiaba nas diferentes etapas de produção e influência da armazenagem. Alim Nutr 2007; 18 (4): 431-8.

GOMES, J. E.; PERECIN, D.; ANTÔNIO, B. G. MARTINS, S. R. Comportamento de propriedades físicas, químicas e reológicas do suco de acerola armazenado a baixa temperatura. Revista Brasileira de Engenharia Agrícola e Ambiental, Campina Grande, v. 5, n. 2, maio, 2001.

GONSALVES, P. E. Livro dos Alimentos. São Paulo: Book, 2002.

HERBÁRIO. Cultivo do Morango. 2005. Disponível em: $<$ http://www.herbario.com.br/dataherb12/morango.htm>. Acesso em: 01 set. 2016.

HORTIFRUTI BRASIL. 100\% Suco: nem tudo é suco nas bebidas de frutas. Cepea - ESALQ / USP, ano 8, n. 81, jun 2009. Disponível em: < http://www.hfbrasil.org.br/br/ revista/acessar/100-suco-nem-tudo-e-suco-na-bebida-defrutas.aspx > Acesso em: 04 out. 2016.

INSTITUTO ADOLFO LUTZ. Métodos Químicos e Físicos para Análises de Alimentos, São Paulo, v. 1, 1985.

INSTITUTE OF MEDICINE. Dietary Reference Intakes for Vitamin C, Vitamin E, Selenium, and Carotenoids. Washington, DC: The National Academies Press, 2000.

LO SCALZO, R. et al. Effect of thermal treatments on antioxidant and antiradical activity of blood orange juice. Food Chem., v. 85, p. 41-47, 2004.

MATTIETO, R. D. A.; LOPES, A. D.; MENEZES, H. C. de. Estabilidade de néctar misto de cajá e umbu. Ciência e Tecnologia de Alimentos, v. 27, n.3, p. 456-463, jul-set, 3007 . 
MORZELlE, M. C.; SOUZA, E. C.; CAROLINA FAGUNDES ASSUMPÇÃO, C. F. BOAS, B. M. V. Desenvolvimento e avaliação sensorial de néctar misto de maracujá (Passiflora edulis Sims) e araticum (Annona crassiflora). Revista Brasileira de Produtos Agroindustriais, Campina Grande, v.13, n.2, p.131-135, 2011.

NUNES, T. P; TRINDADE, M. A.; ORTEGA, E. M. M.; CASTILHO, C. J. C. Aceitação sensorial de reestruturados empanados com filé de peito de galinhas matrizes de corte e poedeiras comerciais. Ciência e Tecnologia de Alimentos, Campinas, p. 841-846, 2006.

PALTRINIERI, G., FIGUEROLA, F. Procesamiento a pequena escala de frutas y hortalizas amazonicas nativas y introducidas. Secretaria Pro-Tempore - Tratado de Cooperacion Amazonica, 1997.

PINHEIRO, A. M. Desenvolvimento de néctares mistos à base de caju (Anacardium occidentale L.) e açaí (Euterpe oleracea mart). Universidade Federal do Ceará. Centro de Ciências Agrárias. Departamento de Tecnologia de Alimentos. Curso de Mestrado em Ciência e Tecnologia de Alimentos, 2008.

PERFEITO, D. G. A.; CORRÊA, I. M.; PEIXOTO, N. Elaboração de bebida com extrato hidrossolúvel de soja saborizada com frutos do cerrado. Revista de Agricultura Neotropical, Cassilândia-MS, v. 4, n. 1, p. 22-28, jan. /mar. 2017.

QUINATO, E. E.; DEGÁSPARI, C. H.; VILELA, R. M. Aspectos nutricionais e funcionais do morango. Visão Acadêmica, Curitiba, v. 8, n. 1, jan- jun., 2007.

SANTOS, G. M.; MAIA. G. A.; SOUSA, P. H. M.; COSTA, J. M. C.; FIGUEIREDO, R. W.; PRADO, G. M. Correlação entre atividade antioxidante e compostos bioativos de polpas comerciais de açaí (Euterpe oleracea Mart). Archivos Latinoamericanos de Nutricion, v. 58, n. 2, p. 187-192, 2008 .

SOUZA, E. C.; DIAS, S. C.; CARDOSO, R. L.; SOUZA, D. T. Elaboração, avaliação físico-química e sensorial da bebida néctar de kiwi. Enciclopédia Biosfera, Centro Científico Conhecer, Goiânia, v.8, N.14; p. 1900, 2012.

SOUSA, P. H. M. Desenvolvimento de Néctares Mistos de Frutas Tropicais Adicionados de Ginkgo biloba e Panax ginseng. Tese Doutorado (Pós-Graduação em Ciência e Tecnologia de Alimentos), Universidade Federal de Viçosa. MG, 153f, 2006.

SEBRAE. Agronegócio: Fruticultura. 2015. Disponível em: $\quad<$ http://www.bibliotecas.sebrae.com.br/chronus/ ARQUIVOS_CHRONUS/bds/bds.nsf/64ab878c176e51
03877bfd3f92a2a68f/\$File/5791.pdf > Acesso em: 04 out 2016.

SOUZA, M. L.; MENEZES, H. C. Avaliação sensorial de cereais matinais de castanha-do-Brasil com mandioca extrusados. Ciência e Tecnologia de Alimentos, Campinas, v. 26, n. 4, p. 950 - 955, 2006.

TONON, R. V.; BRABET, C.; HUBINGER, M. D. Influência da temperatura do ar de secagem e da concentração de agente carreador sobre as propriedades físico-químicas do suco de açaí em pó. Ciência e Tecnologia de Alimentos, v. 29, n. 2, p. 444 - 450, 2009.

VENDRAMINI, A. L.; TRUGO, L. C. Chemical composition of acerola fruit (Malpighia glabra L.) at three stages of maturity. Food Chemistry, London, v. 71, n. 2, p. $195-198,2000$. 